\title{
Elymus athericus (Sea Couch) (Poaceae) and coastal hybrid couch grasses in Scotland.
}

\author{
Michael Wilcox \\ Bradford, W. Yorkshire, UK
}

\section{Corresponding author: michaelpw22@hotmail.com}

This pdf constitutes the Version of Record published on $28^{\text {th }}$ February 2022

\begin{abstract}
A largely herbarium-based study was undertaken to reassess the status of Elymus athericus (Link) Kerguélen (Sea Couch) and the three coastal hybrids E. x drucei (Stace) Stace, E. x laxus (Fr.) Melderis \& D.C. McClint. and E. x obtusiusculus (Lange) Melderis \& D.C. McClint. in Scotland. None of the previous records of $E$. athericus could be confirmed for the country. Verified records of the hybrids are detailed and listed for each relevant vice-county.
\end{abstract}

Keywords: hybrid couch grasses, Elymus, mounted herbarium specimens, distribution

\section{Introduction}

The main aim of this largely herbarium-based study was to determine the validity of records for Elymus athericus (Link) Kerguélen (Sea Couch) and coastal hybrids within Elymus in Scotland. The hybrids were $E . x$ drucei (Stace) Stace (E. athericus $\mathrm{x}$ E. repens (L.) Gould), E. x laxus (Fr.) Melderis \& D.C. McClint. (E. junceiformis (Á \& D. Löve) Hand \& Buttler $x$ E. repens) and E. $x$ obtusiusculus (Lange) Melderis \& D.C. McClint. (E. athericus $\times$ E. junceiforme). The herbarium specimens traced were compared to the records on the Botanical Society of Britain \& Ireland (BSBI) Distribution Database (DDb) (https://database.bsbi.org/), which forms the basis of maps to be included in a forthcoming new atlas of the flora of Britain and Ireland. All appropriate Vice-county Recorders (VCRs) were contacted for more recent vouchers (specimens). As with all DDb records, some are or may be repeats but where possible, in terms of the number of records, these have been left out of the results.

\section{Scope of the study}

The number of vice-counties with at least some coastline or estuarine habitat in Scotland is approximately 36 . Of these, the number with no records on the DDb of any of the taxa under investigation here is $c .12$. However, four of these 12 vicecounties were found to have a herbarium specimen (correct or not) of a taxon relating to this study. These are listed below:

1. For v.c.92 (S. Aberdeen) a specimen named 'E. atherica' was found but it is an error for $E$. junceiformis. 
2. For v.c.98 (Main Argyll) a specimen originally labelled as Triticum acutum DC., 01.07.1874, Toward Point (no recorder) was subsequently re-labelled as Elymus repens. It was redetermined as E. $x$ laxus in this study (Table 2).

3. Despite no record in Table 2, v.c.99 (Dunbarton) has a herbarium specimen with features of $E$. athericus (and appears to be male sterile) from Bowling (which would be approx. NS4472) near Glasgow. It could not be pinned down to a specific hybrid as the material was too poor (no leaves!). It is most likely to be $E . x$ drucei but $E$. $x$ obtusiusculus cannot be ruled out at this stage. There are no records for any hybrid from v.c.99, which suggests this area of coastline needs further attention.

4. A specimen determined as Triticum junceum (with an updated label of Elymus farctus in K) for R. Parnell, Islay, S Ebudes, 20.08.18, v.c.102 (S. Ebudes), has been redetermined as E. $x$ laxus in this study (Table 2). [E. farctus is now reserved for what was Elytrigia juncea subsp. juncea; all our plants are now Elymus junceiformis (Stace, 2019), which was Elytrigia juncea subsp. boreoatlantica (Stace, 2010), but see nomenclature in Cope \& Gray (2009), which treats it as E. farctus.].

\section{Elymus athericus (Sea Couch)}

For Scotland, the New Atlas of the British \& Irish Flora (Preston et al., 2002) mapped about nine hectad dots for $E$. athericus (as Elytrigia atherica) along the coastline between v.c.72 (Dumfries) and v.c.74 (Wigtowns). However, Stace et al. (2015) mapped only one hectad for v.c.74 (presumably accepted) for $E$. athericus, which must relate to the first record for that vice-county. There is another v.c.74 record, which appears to be at least the same tetrad (but with an 8 figure grid reference) but there are no voucher specimens for either, and no further information has come to light. Therefore, it is assumed to be an error for a hybrid or possibly another Elymus taxon in the absence of any specimens.

In contrast to the spread of herbarium specimens, records on the BSBI DDb at the start of the present study (October 2018) showed E. athericus to occur or have occurred in nine Scottish vice-counties. These vice-counties (and the number of records in parentheses) were: v.c.72(10) (see note 1), 73(10), 74(2), 90(2) (see note 2), 95(2), 103(1), 104(1) (see note 3), 105(1) and 107(5). This is a total of approximately 34 records (barring presumed repeats) for this taxon. The notes are as follows:

1. The DDb record that is listed as the first record for v.c.72 (08.09.2007, NY36C) was redetermined as $E$. repens by the author (dried specimen was sent courtesy of the VCR, C. Miles). It brings into question the identity of the other nine records in this vice-county (but see $E . x$ drucei below).

2. Both records for v.c. 90 are now said to be input errors and have since been edited and revised by the VCRs on the DDb (B. Hogarth, pers. comm.). These two $E$. athericus records were changed to Elytrigia juncea (= Elymus junceiformis sensu Stace (2019) but it is not known if they could have been E. $x$ laxus. Records for v.c.90 still need investigating and specimens should be collected.

3. Despite searching for the single v.c.104 record in various herbaria, no trace of it can be found. Originally it was published as Agropyron pungens var. littorale (basically E. athericus) by Heslop-Harrison (1939) but it is likely to be an error, though it might belong to one of the hybrids.

Although there were herbarium specimens with a name relating to $E$. athericus, they were errors mainly for hybrids. A few others clearly had E. athericus in them as 
one parent (and were male sterile), but could not be assigned to a specific hybrid due to the poor quality of the specimen. Therefore, in this study no specimens unambiguously identifiable as $E$. athericus have been traced for Scotland.

\section{Elymus x drucei (Common Couch $x$ Sea Couch)}

In Preston et al. (2002), the hybrid E. $x$ drucei was not mapped though it was suggested that "the hybrid [as Elytrigia $x$ oliveri auct. non (Druce) Melderis \& D.C. McClint.] is mis-recorded as Elytrigia atherica thus obscuring the northern limit of the species". Stace et al. (2015) mapped two hectads for v.c.73, and at least one of these was found as a herbarium specimen. According to the BSBI DDb, this hybrid had $c .16$ records in four Scottish vice-counties as follows: 72(5) (note 1), 73(c. 9) (note 2), 74(1) (note 3) and 90(1) (note 4). Notes as follows:

1. Of the five records in v.c.72, the author received a dried voucher specimen, which according to the DDb is the 'first v.c. record (NY06H, 16.07.2008)'. I redetermined this as Elymus repens f. aristatus (21.12.2018). Therefore, the other four records need to be checked, and like $E$. athericus, there were no herbarium specimens for this vice-county; thus there were none that could be matched to the DDb records. However, during this study several specimens were received from the VCR (C. Miles) in 2019 as 'Elytrigia sp.' or 'Elytrigia x?' - five of which I have determined as E. $x$ drucei, which verifies the presence of the hybrid in v.c.72.

2. In v.c.73, a $1972 \mathrm{DDb}$ record by Milne-Redhead for E. $x$ drucei might be the record originally published as $E$. pycnanthus (E. athericus) as the first record for v.c.73 (Milne-Redhead, 1984), but the DDb record of E. $x$ drucei for Stirling's 1959 record clearly predates it. The identity of both is doubtful as neither could be found in any herbarium. However, in total six herbarium specimens have been redetermined as $E . x$ drucei in this study (none of which were originally identified as this hybrid). Of these, Mackechnie's 1946 specimen (incorrectly labelled on the sheet as $E . x$ laxus) predates all the v.c.73 DDb records. In addition, three other specimens have been determined as $E$. $x$ drucei by the author from material received (courtesy of the VCR, D. Hawker) in 2019. This makes a total of nine specimens determined as $E . x$ drucei for this vice-county (the same number as on the DDb but only one (or two) relate to the DDb records). Some additional searches were made in v.c.73 in 2020 and some of these specimens (kindly sent by the VCR D. Hawker) have been determined as $E$. $x$ drucei by the author.

3. As with $E$. athericus no specimens can be traced for $E$. $x$ drucei in v.c.74.

4. This is the first (and only) record for v.c.90. Again, after enquiring about this record and further investigation it has since been edited by the VCRs due to an earlier error (B. Hogarth pers. comm.).

\section{Elymus x laxus (Common Couch $x$ Sand Couch)}

For E. x laxus c.35 hectad records were mapped in Preston et al. (2002) compared to the improved coverage in Stace et al. (2015), in which c.104 hectads were mapped. Therefore, this is the most frequent Elymus hybrid in Scotland. For this study I verified or (re)determined 109 herbarium specimens of this hybrid (as with all totals, this excludes duplicates). However, surprisingly v.c.74 has c.29 records but again even more surprisingly no verifiable specimens have been found.

Most records are old specimens in herbaria, though identification errors seemed to be frequent for some cases. Records seem to be more biased towards 
field observations only these days, perhaps in part due to a better understanding of the taxa, but it is clear a number of these are errors too. In v.c.90 there are few records, though nine were verified in this study. B. Hogarth kindly provided material, some of which was $E$. $x$ laxus but as it was at the hectad level it could not be incorporated. This does suggest it is being overlooked. In a few vice-counties that have records but no voucher specimens (particularly v.c.74, which has a good number of records), it would be useful to confirm any hybrid with at least one specimen. And perhaps even today all records of any Elymus hybrid in Scotland need expert confirmation. Herbarium specimens are difficult as they are often glued to the sheet, or poor specimens (e.g. no stem leaves or no tillers) and/or badly annotated. Thus even in this study a few may be wrongly assigned (a few $E$. $x$ drucei could be $E$. $x$ obtusiusculus but given the benefit of the doubt based on what was available at the time).

\section{Elymus x obtusiusculus (Sea Couch x Sand Couch)}

The hybrid E. $x$ obtusiusculus has only ever had two doubtful records in Scotland neither of which still appears on the DDb. One of these is for v.c.73 (NX85: 19871999) and one for v.C.74 (NX45: 1880). The hybrid was mapped as a single hectad for v.c.73 in Preston et al. (2002). Thus, the hybrid was included in Stace (2010) where it is said to occur to 'Kirkcudbrightshire' (i.e. v.c.73). Both DDb records were considered doubtful for the Hybrid Flora (Stace et al. 2015; D. Pearman pers. comm.) and therefore they were not mapped.

Although both records are poorly substantiated, it is possible the record for v.c.73 in Preston et al. (2002) might be based on the NX85 record, but no specimen of either record could be found in any herbarium and thus their identity remains unresolved. However, two herbarium specimens of $E$. $x$ obtusiusculus for v.C.73 have come to light; one from Carrick, 1983 (probably c.NX5750) and one from Kirkdale, 1996 (probably c.NX4852/5052) both originally incorrectly identified. I have also determined this hybrid from three tetrads from material sent for determination by the VCR for v.C.73 (D. Hawker) (sent as 'Elytrigia sp./hybrid?') in 2019. This verifies $E$. $x$ obtusiusculus in five tetrads in v.c.73. Some additional searches were made in v.c.73 in 2020 and another specimen received from D. Hawker has been determined as $E$. $x$ obtusiusculus. Although this hybrid is not mapped in Stace et al. (2015), it is still perhaps inadvertently, but fortuitously, in Stace (2019) as occurring to 'Kirkcudbrightshire'.

In addition to the above, a voucher from 1972, (originally as $E . x$ laxus) was found for v.c.74. I have redetermined the specimen as $E$. $x$ obtusiusculus, but clearly from the date (and its location) it is does not relate to the 1880 record in v.c.74. Another herbarium specimen for v.c.75, that was not fully identified, could be this hybrid but equally it could be $E$. $x$ drucei, hence the question marks ('?') in Table 2 for each taxon. Another specimen of this hybrid was found for v.c.85 (from 1902), which was originally identified as $E$. repens, and is at present the earliest and most northerly record of this hybrid in Scotland. This suggests that though it is (currently) rare in Scotland, E. x obtusiusculus has been overlooked. 
Table 2. Summary of the number records on the BSBI DDb (at the start of the study) compared with the number of verified herbarium specimens (VHS) (including additional specimens received in 2019-20). Vice-county numbers shown in bold.

\begin{tabular}{|c|c|c|}
\hline Taxon & $\begin{array}{l}\text { Vice-counties - Number of Records in } \\
\text { Brackets } \\
\text { (BSBI DDb Records : Verified Herbarium } \\
\text { Specimens, VHS) }\end{array}$ & $\begin{array}{l}\text { Totals } \\
\text { DDb : } \\
\text { VHS }\end{array}$ \\
\hline \multicolumn{3}{|c|}{ Elymus athericus } \\
\hline $\begin{array}{l}\text { DDb Records : } \\
\text { Specimens }\end{array}$ & $\begin{array}{l}\mathbf{7 2}(10: 0): \mathbf{7 3}(10: 0): \mathbf{7 4}(2: 0): \mathbf{9 0}(2: 0): \\
\text { 95(2:0): 103(1:0): 104(1:0): 105(1:0): } \\
\text { 107(5:0) }\end{array}$ & $34: 0$ \\
\hline \multicolumn{3}{|c|}{ Elymus $x$ drucei } \\
\hline $\begin{array}{l}\text { DDb Records : } \\
\text { Specimens }\end{array}$ & $\begin{array}{l}\text { 72(5:5): 73(9:11): 74(1:0): 75(0:1(2?)): } \\
\text { 83(0:1): 85(0:1?): } \mathbf{9 0}(1: 0): \mathbf{1 0 0}(0: 1)\end{array}$ & $\begin{array}{l}16: \\
19(+3 ?)\end{array}$ \\
\hline \multicolumn{3}{|l|}{ Elymus x laxus } \\
\hline $\begin{array}{l}\text { DDb Records : } \\
\text { Specimens }\end{array}$ & 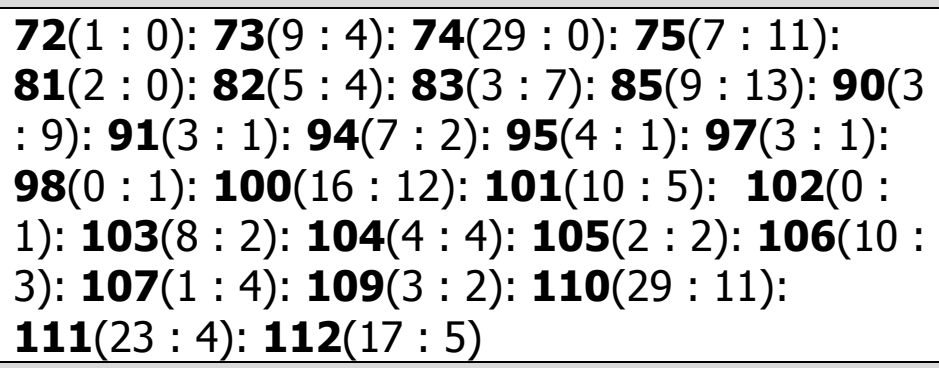 & $208: 109$ \\
\hline \multicolumn{3}{|l|}{$\begin{array}{l}\text { Elymus } x \\
\text { obtusiusculus }\end{array}$} \\
\hline $\begin{array}{l}\text { DDb Records : } \\
\text { Specimens }\end{array}$ & 73(1?:6): 74(1?: 1): 75(0:(1?)): 85(0:1): & $\begin{array}{l}2 ?: \\
8(+1 ?)\end{array}$ \\
\hline
\end{tabular}

NB: although some DDb records may be less, more or equal in number to herbarium specimens, very few actual specimens could be found that matched DDb records; thus they are comparable in number only. The number of DDb records and herbarium specimens is approximate as some appear to be repeated records or duplicate specimens respectively, and where deemed to be so, most have been left out. In v.c.73, for $E . x$ obtusiusculus, the DDb record with a '?', (i.e. 1? : 6), relates to the NX85 record and similarly, the record with a '?' (i.e. 1? : 1) for v.c.74, relates to the old 1880 record. Neither could be found in a herbarium so their identity remains unsubstantiated. In v.c.75 there is one herbarium specimen that was redetermined as $E$. $x$ drucei, hence it is retrospectively new to this vice-county (and included under $E . x$ drucel). However, another specimen from this vice-county is a hybrid (but not $E$. $x$ laxus, in my opinion) but it could not be confidently identified as $E$. $x$ druceior $E$. $x$ obtusiusculus, hence the ' 2 ?' for the former and the ' 1 ?' for the latter respectively in Table 2.

\section{Conclusions}

The presence of $E$. athericus in Scotland has always been controversial and in this study it has not been identified from any existing specimens. However, it is concluded, mainly from herbarium specimens (but also from a few specimens sent to 
the author in 2019/20), that all three Elymus hybrids included in the study occur in Scotland. Elymus $x$ drucei, with $c .19$ specimens has been found from five (six?) vicecounties. The earliest record is 1911 from v.c. 83 and is at present the most northerly record in Scotland; however, the identification of some specimens from near Inverkeithing and St David's (Fife) in v.c.85 (1913) that appear to be $E . x$ drucei would be the most northerly if modern vouchers could be found. Elymus $x$ laxus has $c .109$ verified (all herbarium) specimens from $c .23$ vice-counties with the earliest record being c.1801-1806? The third hybrid E. $x$ obtusiusculus, has been determined from 7 or 8 specimens in at least three vice-counties. Surprisingly, there were no verifiable specimens from v.c.74 for $E$. athericus or any hybrid due to poor material. Some vice-counties have records but no voucher specimens so this reduced the number of vice-counties with confirmed records. Further work is needed to resolve the Scottish distribution of these taxa. The author welcomes specimens that include basal parts and or tillers for determination.

\section{Acknowledgements}

Thanks go to each herbarium that sent material to Manchester University Museum: Particular thanks go to Lindsey Loughtman \& Rachel E. Webster (MANCH) for arranging the loans; John Hunnex \& Fred Rumsey (BM); D. Harris (E); Keith Watson, (GL/GLAM); H. Pardoe (NMW); Dr Siobhan Cooke-Miller Stromness Museum (STS); A.J. Paton and Alison Moore (K); and Serena Marner (OXF). Thanks also go to Robert Baxter (Durham University), Tom Humphrey (BSBI Database Officer), Arthur Copping, John Durkin, R.G. Ellis, Eric F. Greenwood, Louise Marsh, Chris Metherell, D.A. Pearman \& Michael Philip, Clive Stace (all BSBI) and Alan Elliott, Erzsebet Gyongy \& Graham Hardy (all RBG-E). Thanks also to the following VCRs (v.c. number in brackets): Chris Miles (v.c.72), David Hawker (v.c.73), David Lang (v.c.75), K.J. Watson (v.c.76), M.E. Braithwaite (v.c.81), E.H. Jackson (v.c.82), B. Sumner (v.c.83), A.S. Edwards \& G.H. Ballantyne (v.c.85), Barbara Hogarth (v.c.90), D. Welch (v.c.91, v.c.93), A.G. Amphlett (v.c.94), Ian Green (v.c.95), C. Farmer \& G. Rothero (v.c.98), A.C. Hannah (v.c.100), Lynne Farrell (v.c.103), Stephen Bungard (v.c.104), Duncan Donald (v.c.105), Mick Crawley (v.c.107), J. Crossley (v.c.111) and P. Harvey (v.c.112).

\section{References}

Cope, T.A. \& Gray, A. 2009. Grasses of the British Isles. BSBI Handbook No. 13. London: Botanical Society of the British Isles.

Heslop-Harrison, J.W. 1939. The flora of the Isles of Rhum, Eigg, Canna, Sanday, Muck, Eilean nan Each, Hyskeir, Soay and Pabbay. Proceedings of the University of Durham Philosophical Society 10: 87-123.

Milne-Redhead, H. 1984. In: Plant Records. Watsonia, 15: 125-143.

Preston, C.D., Pearman, D.A. \& Dines, T.D. 2002. New Atlas of the British \& Irish Flora. Oxford: Oxford University Press.

Stace, C.A. 2010. New Flora of the British Isles, $3^{\text {rd }}$ ed. Cambridge: Cambridge University Press.

Stace, C.A. 2019. New Flora of the British Isles. $4^{\text {th }}$. ed. Middlewood Green, Suffolk: C \& M Floristics. 
Stace, C.A., Preston, C.D. \& Pearman, D.A. 2015. Hybrid Flora of the British Isles. Bristol: Botanical Society of Britain \& Ireland.

Copyright retained by author(s). Published by BSBI under the terms of the Creative Commons Attribution 4.0 International Public License.

ISSN: $2632-4970$

https://doi.org/10.33928/bib.2022.04.027 